\title{
Potential application of dental stem cells in regenerative reconstruction of oral and maxillofacial tissues: a narrative review
}

\author{
Puhan He ${ }^{1}$, Qunzhou Zhang ${ }^{1}$, Faizan I. Motiwala ${ }^{2}$, Rabie M. Shanti ${ }^{1,3,4}$, Brian M. Chang ${ }^{1,5}$, Anh D. Le ${ }^{1,3}$ \\ ${ }^{1}$ Department of Oral \& Maxillofacial Surgery \& Pharmacology, University of Pennsylvania School of Dental Medicine, Philadelphia, PA, USA; \\ ${ }^{2}$ University of Pennsylvania School of Dental Medicine, Philadelphia, PA, USA; ${ }^{3}$ Department of Oral \& Maxillofacial Surgery, Penn Medicine \\ Hospital of the University of Pennsylvania, Philadelphia, PA, USA; ${ }^{4}$ Department of Otorhinolaryngology-Head and Neck Surgery, University of \\ Pennsylvania Perelman School of Medicine, Philadelphia, PA, USA; ${ }^{5}$ Division of Restorative Sciences, University of Pennsylvania School of Dental \\ Medicine, Philadelphia, PA, USA \\ Contributions: (I) Conception and design: P He, Q Zhang, AD Le; (II) Administrative support: All authors; (III) Provision of study materials or \\ patients: All authors; (IV) Collection and assembly of data: All authors; (V) Data analysis and interpretation: All authors; (VI) Manuscript writing: All \\ authors; (VII) Final approval of manuscript: All authors. \\ Correspondence to: Anh D. Le, DDS, PhD. Department of Oral \& Maxillofacial Surgery, Penn Medicine Hospital of the University of Pennsylvania, \\ Philadelphia; Department of Oral \& Maxillofacial Surgery and Pharmacology, University of Pennsylvania School of Dental Medicine, 240 South \\ 40th Street, Philadelphia, PA 19104, USA. Email: Anh.Le@pennmedicine.upenn.edu; Qunzhou Zhang, PhD. Department of Oral \& Maxillofacial \\ Surgery and Pharmacology, University of Pennsylvania School of Dental Medicine, 240 South 40th Street, Philadelphia, PA 19104, USA. \\ Email: zqunzhou@upenn.edu.
}

Background and Objective: Oral and maxillofacial (OMF) defects caused by congenital conditions, injuries, ablative surgery for benign and malignant head \& neck tumor, can often lead to OMF deformities and malfunctions in speech, mastication/chewing, and swallowing as well as have deleterious psychological effects and socioeconomic burdens to patients. Due to the unique complex 3D geometry of the head and neck region, reconstruction and rehabilitation of OMF defects remain a major challenge for OMF surgeons. The purpose of this narrative review is to update the information on the biological properties and functions of mesenchymal stem cells derived from various dental tissues (dental-MSCs) and their potential application in tissue engineering (TE) and regenerative reconstruction of OMF tissues.

Methods: A data-based search was performed by using PubMed database whereby articles published between 2000 and 2021 in English were included in the search with the following key words: dental stem cells, OMF reconstruction, OMF TE and regeneration.

Key Content and Findings: Currently, the advancement in stem cell biology, biomaterial science, and TE technology has demonstrated the significant potential application of stem cell-based therapy in regenerative reconstruction and rehabilitation of OMF defects. However, no stem cell-based product or device has been translated into clinical application to replace microsurgical free tissue transfer, the current mainstay of care in the reconstruction of OMF defects.

Conclusions: Currently, microsurgical free tissue transfer remains the gold standard mainstay of care for the reconstruction of OMF defects due to their abundant blood supply and flexibility for transplantation. However, several major challenges, such as the limited availability, the requirement of a second surgery, donor site morbidity, and the risk of free flap failure, have promoted the development of novel approaches. Due to the advancement in stem cell biology, biomaterial science, and TE technology, stem cell-based regenerative therapy is emerging as a promising therapeutic approach for a variety of diseases, including regenerative reconstruction and rehabilitation of OMF defects. In this narrative review, we update on the characteristics and biological functions of mesenchymal stem cells derived from various dental tissues (dental-MSCs) and their released cell-free products, extracellular vesicles (EVs). We also highlighted their potential application in $\mathrm{TE}$ and regenerative reconstruction of $\mathrm{OMF}$ defects in animal models and clinical studies and the potential challenges in this field. 
Keywords: Dental stem cells; extracellular vesicles (EVs); tissue engineering (TE); regenerative therapy; oral and maxillofacial (OMF) defect

Received: 01 February 2021; Accepted: 16 June 2021; Published: 10 June 2022.

doi: $10.21037 /$ fomm-21-10

View this article at: https://dx.doi.org/10.21037/fomm-21-10

\section{Introduction}

Reconstructive surgery is a growing aspect of oral and maxillofacial (OMF) surgery specialty. Among others, OMF surgeons are especially equipped to manage deformities and defects of the midface/maxilla, oromandibular region, and the temporomandibular joint (1-4). Defects in the head and neck may involve insult to multiple tissue types including bones, cartilage, muscle, skins, nerves and blood vessels. The complex anatomy and the presence of specialized organs such as the tongue, periodontium, and teeth (5-8) make reconstruction of this region especially challenging. OMF defects and deformities may be acquired, as a sequela of trauma and surgical resection due to neoplasm, infection or necrosis; or they may be congenital, as is in the case of cleft lips and palates (2). These defects result in facial disfigurement, speech impairment, mastication and swallowing difficulties, posing a significant psychological and economical burden to the patient and family (2,7,9-12). Reconstruction offers possibility of restoring function and cosmesis, and thereby improving overall quality of life $(9,13,14)$.

In recent years, the development and advancement of state-of-the-art technologies and approaches, such as navigation, virtual surgical pre-planning (VSP), 3D printing technology, and microsurgical techniques have significantly advanced the field of OMF reconstruction $(8,15)$. A successful reconstruction and functional rehabilitation of OMF defects rely on multiple factors, such as the type of defect, the health status of patients, and the treatment modality $(13,15)$. Treatment modalities may include primary closure, healing by secondary intention, autografts, allograft, prosthesis and flaps. Locoregional flaps and vascularized soft-tissue and bone/composite free flaps are the mainstay of treatment for reconstruction of large OMF defects (16-20). However, donor site morbidity, and the inability to restore specialized tissue such as taste, sensory and periodontium pose challenges in reestablishing premorbid form and function (19). Therefore, further investigation on reconstruction surgery and functional rehabilitation techniques is requisite $(13,15)$.

In the last decade, advancements in tissue engineering (TE), biomaterial science, and stem cell biology, have shed new light on the development of novel approaches for OMF reconstruction and functional rehabilitation (8). Regenerative medicine (RM) aims to use multiple approaches to replace or regenerate damaged cells, tissues and organs; or to stimulate the body's endogenous repair mechanisms (21). As an emerging field, RM integrates TE, material science, and stem cell biology to generate stem cell-based TE/RM products to meet the increasing clinical demand for tissue regeneration/reconstruction, including regenerative rehabilitation of OMF defects (22-24). This article reviews recent progress and potential towards the clinical application of stem cells, particularly, oral tissue-derived stem cells, in reconstructive surgery and regenerative rehabilitation in patients with OMF defects. We present the following article in accordance with the Narrative Review reporting checklist (available at https:// fomm.amegroups.com/article/view/10.21037/fomm-21$10 / \mathrm{rc})$.

\section{Methods}

In this narrative review, we searched the PubMed database using the following key words: dental stem cells, OMF reconstruction, OMF TE, oral craniofacial and maxillofacial tissue regeneration. The following $\mathrm{MeSH}$ terms were utilized to aid in the literature search as well: head and neck neoplasms, oral surgery, mesenchymal stem cells (MSCs), and TE. The published articles with full-text from Jan 2000 to Jan 2021 were included (Table 1) dental stem cells, OMF reconstruction, OMF tissue engineering and regeneration.

\section{Discussion}

MSCs

MSCs represent a population of multipotent postnatal 
Table 1 The search strategy summary

\begin{tabular}{|c|c|}
\hline Items & Specification \\
\hline Databases and other sources searched & PubMed database \\
\hline $\begin{array}{l}\text { Search terms used (including MeSH and free text search terms and } \\
\text { filters). Note: please use an independent supplement table to present } \\
\text { detailed search strategy of one database as an example }\end{array}$ & $\begin{array}{l}\text { Dental stem cells, oral and maxillofacial reconstruction, oral and } \\
\text { maxillofacial tissue engineering and regeneration }\end{array}$ \\
\hline Inclusion and exclusion criteria (study type, language restrictions etc.) & $\begin{array}{l}\text { Articles written in English related to dental stem cells and oral and } \\
\text { maxillofacial reconstruction were included. Any articles not written } \\
\text { in English were excluded. No specific study type was excluded }\end{array}$ \\
\hline $\begin{array}{l}\text { Selection process (who conducted the selection, whether it was } \\
\text { conducted independently, how consensus was obtained, etc.) }\end{array}$ & The selection process was done by Dr. Qunzhou Zhang \\
\hline
\end{tabular}

stem cells with self-renewal and multipotent differentiation capabilities. The first isolated and most well characterized source of MSCs was from bone marrow (25). They are described as fibroblast-like in morphology and able to form adherent "colony-forming units-fibroblastic" (CFU-F) $(26,27)$. Thereafter, the International Society of Cell \& Gene Therapy (ISCT) defined human MSCs based on three minimal criteria,: (I) an adherent fibroblast-like appearance; (II) the expression of a panel of specific mesenchymal cell surface molecules such as CD73, CD90, and CD105, while lacking the expression of hematopoietic cell markers such as CD34, CD45, CD11b, CD14, CD19, and of human leukocyte antigen-D related (HLA-DR or HMC-II) surface molecules; (III) the potential to differentiate into trilineage of mesodermal cells, including osteocytes, adipocytes, and chondrocytes (28). In addition to bone marrow, a similar population of MSCs have been isolated and characterized from various types of connective tissues throughout the body, including but not limited to, adipose tissue (29), lung (30), skin (31), peripheral blood (32), synovial fluids (33), and skeletal muscle (34). MSCs have also been identified from placenta (35), umbilical cord (36) and more recently, orofacial and dental tissues as well $(37,38)$. In the last two decades, numerous preclinical and clinical studies have demonstrated that endogenous MSCs play essential roles in tissue homeostasis and remodeling (39), while exogenous MSCs expanded ex vivo have been widely utilized in TE/RM. In addition to facilitating repair/regeneration of damaged tissue through its multipotency, MSCs have also been sourced for its immunomodulatory properties to treat inflammatory diseases such as graft-versus host disease, multiple sclerosis, Crohn's disease, amyotrophic lateral sclerosis, among others (40-42).

\section{New paradigm of MSC action: the secretome and extracellular vesicles (EVs)}

Initially, it was thought that MSC-mediated regenerative therapeutic potentials are due to their multipotency as replacement cells to those injured/damaged cells. However, accumulating evidence indicates that clinical improvement can be achieved despite a limited number of MSCs engrafted and retained in the targeted tissues as well as the short survival time following their systemic or local transplantation. This suggests that MSC-mediated benefits might be due to their paracrine trophic effects (43). A growing body of evidence has demonstrated that MSCs exert their regenerative therapeutic effects mainly through their potent immunomodulatory/anti-inflammatory functions and pleiotropic effects mediated by their paracrine secretion of an array of soluble factors, such as cytokines, growth factors, hormones, miRNAs, and other bioactive small molecules. These factors have diverse biological functions, including but not limited to: (I) modulating both the local and systemic immune systems; (II) promoting angiogenesis; (III) promoting proliferation and survival of specific tissue resident cells; (IV) anti-apoptosis; (V) antioxidant effects, and so on (42-44). In 2019, ISCT accordingly added two more criteria to define MSCs, including their tissue of origin and related functional assays to determine their potential mechanism of action (MOA) (45).

EVs are nano-sized particles secreted by all types of cells, 




Figure 1 Sources, properties, and biological functions of dental mesenchymal stem cells. Portions of this figure were made using templates from SMART SERVIER MEDICAL ART (https://smart.servier.com) and Biorender (https://biorender.com/). DPSC, dental pulp stem cells; SHED, stem cells from human exfoliated deciduous teeth; PDLSC, periodontal ligament stem cell; GMSC, gingiva-derived mesenchymal stem cell; SCAP, stem cells derived from apica papilla; DFSC, dental follicle stem cell; TGSC, tooth germ stem cell; OMF, oral and maxillofacial; CFU-f, colony forming unit-fibroblasts; CM, conditioned medium; EVs, extracellular vesicles; PBMC, peripheral blood mononuclear cell.

including MSCs, which play critical roles in intercellular communication through horizontal transfer of cargoes containing lipids, nucleic acids (DNA and RNA), proteins, and metabolites, etc. (46). Due to their biogenesis, size, and surface markers, EVs are generally classified into ectosomes and exosomes (47). Ectosomes, including microvesicles, microparticles, and large vesicles, are generated by the direct outward budding of the plasma membrane with a size ranged from $~ 50$ to $1,000 \mathrm{~nm}$ in diameter, while exosomes are derived from endosomes with a size ranged from 40 to $160 \mathrm{~nm}$ in diameter ( 100 $\mathrm{nm}$ in average) (46). Accumulating evidence has shown that mesenchymal stem cell EVs (MSC-EVs) have pleiotropic effects on various biological processes of targeted cells, among which are immune responses, apoptosis, survival and proliferation, migration, lineage-specific differentiation, and angiogenesis $(44,46,48)$. Numerous pre-clinical studies have shown that systemic or local administration of MSCEVs display potent regenerative and therapeutic potentials for a variety of pathological conditions, thus supporting the notion that MSC-EVs could provide promising avenues to generate cell-free products applicable for TE and RM $(44,48)$, including their application in OMF TE and regeneration (49).

\section{MSCs derived from dental tissues}

Of interest, a unique population of MSCs has also been isolated from various dental tissues (Figure 1). As early as in 2000, the first type of MSCs was isolated from human 


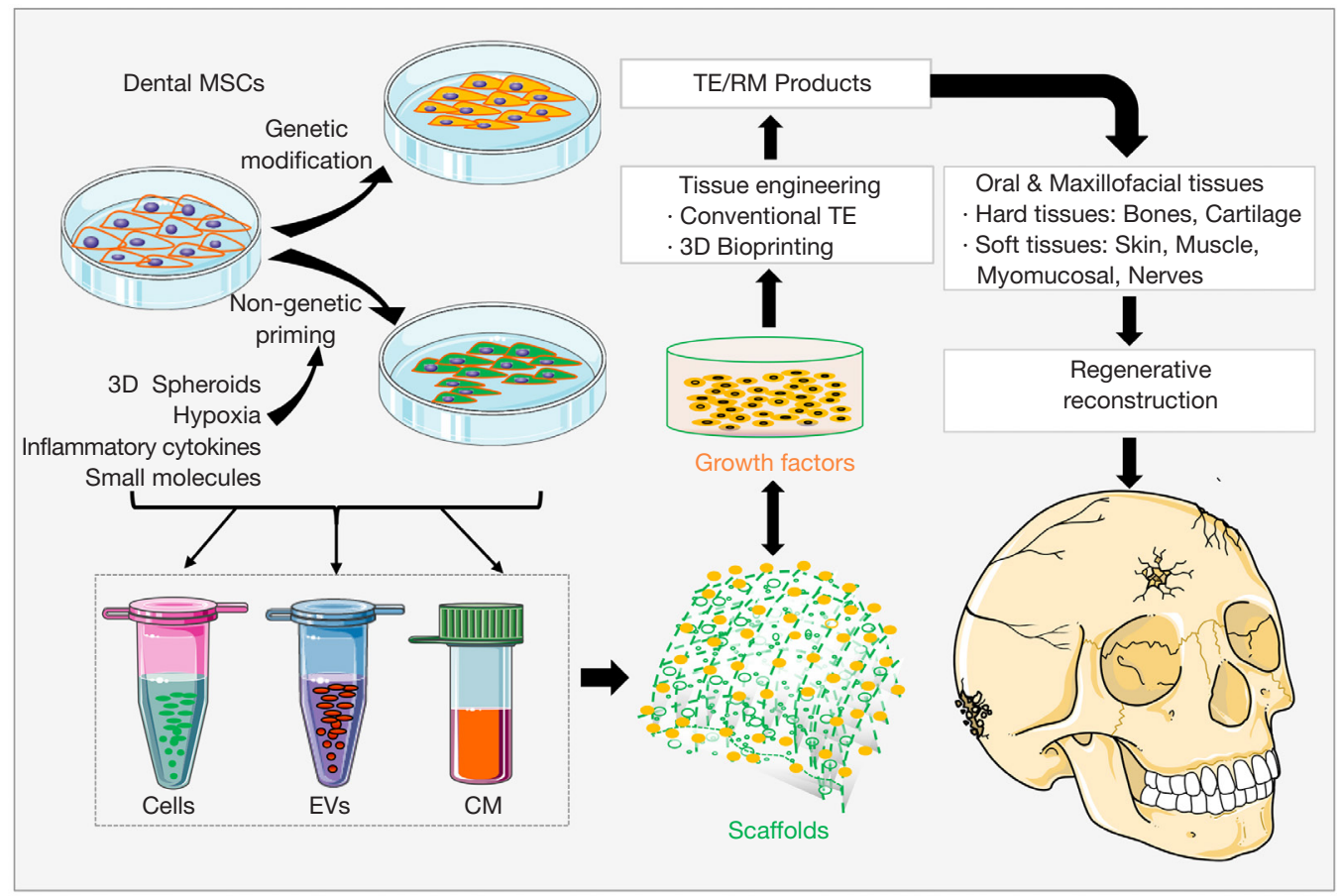

Figure 2 Potential application of dental MSCs and their cell-free products in tissue engineering and regenerative reconstruction of oral \& maxillofacial tissue defects. Portions of this figure were made using templates from SMART SERVIER MEDICAL ART (https://smart.servier. com). MSC, mesenchymal stem cell; CM, conditioned medium; EVs, extracellular vesicles; TE/RM, tissue engineering/regenerative medicine.

dental pulp stem cells (DPSC) (50). Afterwards, MSCs have been isolated from other dental tissues, including exfoliated deciduous teeth (SHED) (51), periodontal ligament (PDLSC) (52), gingiva (GMSC) (53), apical papilla (SCAP) (54), dental follicle (DFSC) (55), and tooth germ stem cells (TGSC) (56). Similar to other sources of MSCs, such as BMSCs and ADSCs, these dental MSCs also possess potent self-renewal, multipotent differentiation, and immunomodulatory capacities $(37,57,58)$ (Figure 1). During vertebrate embryonic development, most cranial/dental tissues are derived from neural crest (NC) $(59,60)$. In recent years, studies have shown that a subpopulation of multipotent MSCs derived from human DPSCs $(50,61)$, oral mucosa and gingiva (62-65), apical papilla (APSC) (66), DFSC (67), and PDLSC (68), are endowed with NC stem cell-like properties. Interestingly, as compared with mesodermderived MSCs, NC-derived MSC counterparts showed elevated differentiation potentials into neural cells and chondrocytes and enhanced immunomodulatory and anti-inflammatory effects both in vitro and in vivo (69). These studies suggest that dental tissues serve as important reservoirs of adult NC-derived multipotent stem cells. Recently, several lines of evidence have also demonstrated the pleiotropic effects and regenerative and therapeutic potentials of EVs secreted by dental-MSCs (70-72) (Figure 1). Together, dental MSCs represent an easily accessible source of MSCs with great potential application in TE/ $\mathrm{RM}$, particularly, in OMF tissue regeneration (49).

\section{Application of dental MSCs in TE and regeneration of OMF tissues}

In 1997 Charles Vacanti stunned the world with his "Vacanti Mouse", a landmark in TE that Vacanti and his team successfully grew an ear on the back of a nude mouse following transplanation of a polymer-human chondrocyte construct (73). This fueled further advancement in TE demonstrating the potential to restore tissues with ex vivo fabricated constructs using different types of scaffold materials and living cells. Classically, TE relies on a "Regenerative Trinity" which involves the combination of scaffolds/biomaterials, living cells, and signaling/bioactive factors to engineer tissue constructs $(21,22,24)$ (Figure 2). 
In the last decade, significant progress has been made in the field of TE and regenerative reconstruction of oral and craniofacial tissues due to the advancement of biomaterial science, TE technology, and the understanding of stem cell biology (22-24). Herein, we focus on describing the potential application of dental MSCs in TE and regeneration of OMF tissues.

\section{DPSCs and stem cells from human exfoliated deciduous teeth (SHED)}

Human pulp stem cells include precursor cells isolated from dental pulp tissues of human extracted permanent teeth (DPSC) and SHED (74,75). As the first type of MSCs isolated from dental tissues (50), substantial progress has been made in understanding their biological properties. Their multipotency and immunomodulatory functions suggest their potential application in TE and regenerative therapy of a wide spectrum of pathological conditions $(74,75)$. In fact, the application of DPSCs and SHEDs alone or in combination with different scaffolds in regeneration of oral and craniofacial tissues has been extensively explored in various rodent and large animal models as well as in some pilot clinical studies (Table 2).

In a rat mandibular ramus critical bone defect model, Zhang et al. showed that DPSC-seeded E1001(1k)/ $\beta$-TCP scaffolds support the rapid regeneration of osteo-dentinlike mineralized jaw tissue, suggesting a promising new therapy for alveolar jaw bone repair and regeneration (80). Jahanbin et al. reported that transplantation SHED mixed with collagen matrix significantly enhanced new bone formation in a maxillary alveolar defect model in Wistar rats (82). Another study by Riccio et al. showed that silk fibroin/DPSC constructs exhibited strong regenerative capacity for correcting large cranial defects in rats (81). The potential of DPSC and SHED in cranial and maxillofacial bone regeneration have been further demonstrated in rabbit models (Table 2). Using a mandibular distraction model in New Zealand white rabbits, Alkaisi et al. showed that SHED can significantly enhance mandibular distraction osteogenesis (DO) (79). Most recently, Zhang et al. showed that transplantation of hDPSC/endothelial cells (HUVEC)seeded E1001(1K)/ $\beta$-TCP scaffolds significantly enhance bone formation in critical-sized alveolar bone defects in an in vivo rabbit mandible defect model (77). GutiérrezQuintero reported that transplantation of DPSCs seeded with hydroxyapatite matrix and polylactic polyglycolic acid (HA/PLGA) scaffolds also significantly augmented bone regeneration in bilateral mandibular critical-sized defects in rabbits (78). Implantation of DPSCs mixed with biodegradable poly[ethylene glycol]-diacrylate [PEGDA] hydrogels thiol-acrylate hydrogels also facilitated cranial bone regeneration in rabbits (76). Most recently, Ghavimi et al. reported that DPSCs mixed with nanofibrous asymmetric collagen/curcumin membrane containing aspirin-loaded PLGA nanoparticles can promote guided bone regeneration (GBR) in the defects created in both sides of the dog's jaw (83).

Critical-sized calvarial bone defect model in rodents is another popularly used model to evaluate the bone regenerative potentials of MSCs. Several studies have demonstrated the regenerative effects of DPSCs and SHEDs alone or in combination with different scaffolds on bone formation in critical-sized calvarial defects in mice (84-88) and rats (89-92). In addition, Wongsupa et al. reported that implantation of the bioengineered constructs of DPSCs in poly- $\varepsilon$-caprolactone (PCL)-biphasic calcium phosphate (BCP) scaffolds augment new bone formation in rabbit calvarial defects (93). In large animal models of dental implant surgeries, it has also been shown that DPSCs increases new bone formation and vertical bone height in experimental sheep (94) and dog (95) models. Most recently, Talaat $e t$ al. reported the potential use of DPSCs embedded in nanocellulose-chitosan thermosensitive hydrogel for cartilage regeneration (96).

In addition to the potential application of DPSCs and SHED in reconstruction of hard craniofacial and maxillofacial tissues, their use in reconstruction of soft OMF tissues, such as periodontal defects $(97,99)$ and craniofacial nerves (100-102), has been suggested as well. For instance, Li et al. reported that autologous DPSCs derived from inflammatory dental pulps (DPSC-IPs) with $\beta$-TCP promote reconstruction of periodontal defects in minipig (97). $\mathrm{Hu}$ et al. reported that either direct DPSC injection or implantation of DPSC cell sheet significantly regenerated periodontal bone in swine even though DPSC sheet had more bone regeneration capacity compared with DPSC injection (98). In a pilot clinical studies with two patients with periodontal intrabony defects, the same group reported that DPSCs-IPs generated new bones to repair the periodontal defects 9 months after surgical reconstruction (99). For craniofacial nerve regeneration, implantation of DPSCsheets and DPSCs infilled in PLGA artificial nerve conduits significantly promoted crush-injured and segmental defect models of rat facial nerves, respectively $(100,101)$. The superior laryngeal nerve (SLN) plays an essential role in swallowing. A recent study showed that systemic 
Table 2 Application of DPSC/SHED in OMF tissue regeneration

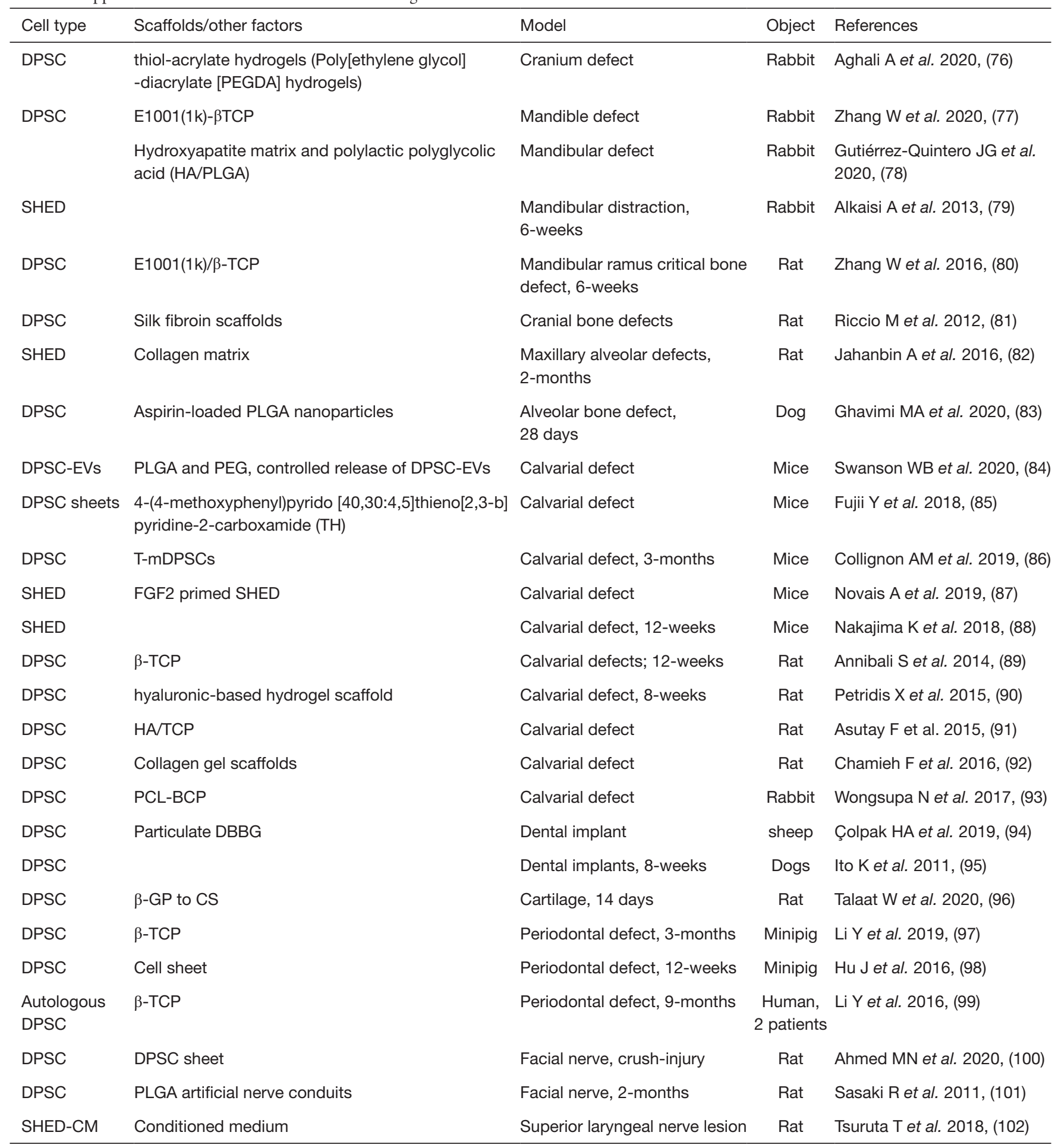

DPSC, dental pulp stem cells; SHED, stem cells from human exfoliated deciduous teeth; OMF, oral and maxillofacial; PLGA, poly(lactic-

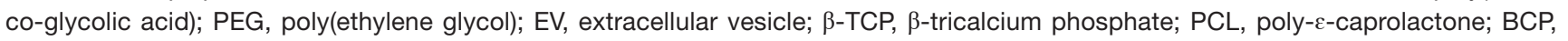
biphasic calcium phosphate; DBBG, deproteinized bovine bone graft; GP, glycerophosphate; CS, chitosan. 
Table 3 Application of PDLSCs in OMF tissue regeneration

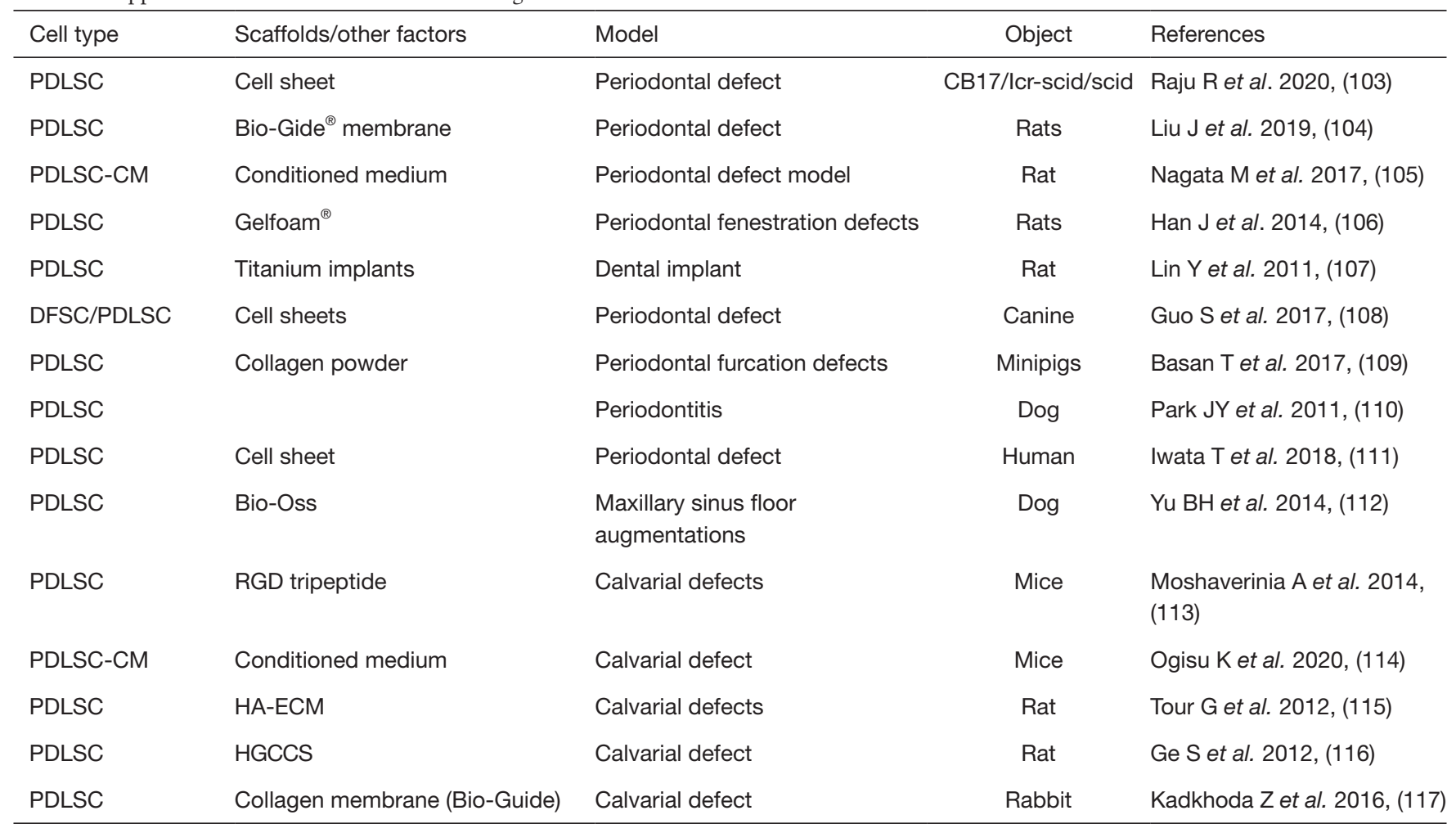

PDLSC, periodontal ligament stem cell; OMF, oral and maxillofacial; CM, conditioned medium; DFSC, dental follicle stem cell; RGD, arginine-glycine-aspartic acid; HA-ECM, hydroxyapatite-incorporated extracellular matrix; HGCCS, nanohydroxyapatite-coated genipinchitosan conjunction scaffold.

administration of SHED-conditioned media (SHED-CM) could promote axonal regeneration and functional recovery of injured SLN (102). Altogether, these compelling findings have elucidated the potential application of DPSCs and SHED in TE and regenerative reconstruction of craniomaxillofacial defects.

\section{PDLSC}

Since the initial isolation of PDLSCs (52), a number of studies have extensively investigated their extraordinary biological properties and regenerative potentials. Of particular significance is the application of PDLSCs cell sheets alone or in combination with scaffolds in rodent periodontal defect models (Table 3) (103-106) to regenerate the periodontium, a complex composed of root cementum, alveolar bone, gingiva, and periodontal ligament (PDL) (118). For instance, transplantation of PDLSCs combined with Bio-Gide ${ }^{\circledR}$ collagen membrane or GelFoam significantly increased bone volume and average thickness of bone trabecular bone in a rat periodontal defect model, with enhanced regeneration of cementum-like structure and formation of collagen fiber formation $(104,106)$. Nagata et al. reported that directly local application of PDLSCderived conditioned medium (CM) could also enhance rat periodontal regeneration by reducing $\mathrm{TNF}-\alpha$ production thereby suppressing the inflammatory responses (105). Lin et al. reported that transplantation of PDLSCs with dental implants can organize periodontal tissues at the site of previously lost teeth in rats (107). In periodontal defect models of large animals, such as canines $(108,110)$ and minipigs (109), transplantation of PDLSC sheets or PDLSCs combined with collagen powder over surgically created periodontal defect sites promote periodontal regeneration even under an inflammatory microenvironment (108). In the advanced periodontitis model in dog, where a circumferential defect involving the alveolar bone, periodontal ligament and cementum was surgically created, autologous PDLSCs showed the best regenerative capacity for these structures as well as peripheral nerve and blood vessel (110). Furthermore, 
Table 4 Application of GMSCs in oral \& craniofacial tissue regeneration

\begin{tabular}{|c|c|c|c|c|}
\hline Cell type & Scaffolds/other factors & Model & Object & References \\
\hline GMSC-EV & TNF- $\alpha$ pre-conditioned & Periodontal & Mice & Nakao Y et al. 2020, (123) \\
\hline GMSC & & Class III furcation defects & Dog & Yu X et al. 2013, (124) \\
\hline GMSC & IL-1Ra HA-sECM & Periodontal defects & Minipig & $\begin{array}{l}\text { Fawzy El-Sayed KM et al. } \\
\text { 2015, (125) }\end{array}$ \\
\hline GMSC & $\begin{array}{l}\text { Alginate-based adhesive, photocrosslinkable, and } \\
\text { osteoconductive hydrogel biomaterial (AdhHG) }\end{array}$ & Rat peri-implantitis model & Rat & $\begin{array}{l}\text { Hasani-Sadrabadi MM et al. } \\
\text { 2020, (127) }\end{array}$ \\
\hline GMSCs & Hydrogel scaffold PuraMatrix ${ }^{\mathrm{TM}}$ & Maxillary alveolar defect & Nude rats & Kandalam U et al. 2020, (128) \\
\hline GMSC & Type I collagen & $\begin{array}{l}\text { Mandibular defect } \\
\text { Calvarial defect }\end{array}$ & Rat & Wang F et al. 2011, (129) \\
\hline GMSC-EV & PLA 3D printing & Calvarial defect & Rat & Pizzicannella J et al. 2019, (131) \\
\hline GMSC-EV & (3D) engineered scaffolds (PLA) & Calvarial defect & Rat & Diomede F et al. 2018, (132) \\
\hline GMSC & & Palatal wound & Mice & Su Y et al. 2018, (133) \\
\hline Fetal GMSCs & & Gingival defects & Rat & Li J et al. 2018, (134) \\
\hline GMSC-EV & SIS-ECM & Tongue defects & Rat & Zhang Y et al. 2019, (135) \\
\hline GMSC & SIS-ECM & Tongue defects & Rat & Xu Q et al. 2017, (136) \\
\hline GMSC & 3D spheroid, 3D bioprinting & Facial nerve & Rat & Zhang Q et al. 2018, (137) \\
\hline GMSC-NCC & AxoGuard nerve conduits & Facial nerve & Rat & Zhang Q et al. 2018, (138) \\
\hline
\end{tabular}

GMSC, gingiva-derived mesenchymal stem cell; CM, conditioned medium; EV, extracellular vesicle; HA-sECM, hyaluronic acid synthetic extracellular matrix; PLA, polylactic acid; SIS-ECM, small intestinal submucosa extracellular matrix.

a single-arm and single-institute clinical study has demonstrated the safety and efficacy of autologous PDLSC sheets in 10 cases of patients with periodontitis at 6-months following transplantation, with sustained therapeutic effects for a mean follow-up period of $55 \pm 19$ months and no serious adverse events observed (111).

In addition to the potent periodontal regenerative properties, preclinical studies using rodents and large animal models have shown that PDLSCs can induce craniofacial bone regeneration in rodent and large animal models (Table 3). In a dog model of bilateral maxillary sinus floor augmentation, Yu et al. showed that seeding of PDLSCs or BMMSCs onto Bio-Oss can promote bone formation and mineralization and maintain the maximum volume of the augmented maxillary sinus (112). Meanwhile, several studies have shown that transplantation of PDLSC CM or various PDLSC-seeded scaffolds can significantly enhance bone repair/regeneration in calvarial defects in mice $(113,114)$, rat $(115,116)$, and rabbit $(117)$. These compelling findings have demonstrated that PDLSCs have potentials in the regeneration/reconstruction of oral maxillofacial tissues, particularly, lost/damaged support tissue in the periodontium complex, including the alveolar bone, periodontal ligament, and cementum (119).

\section{Gingiva and oral mucosa-derived MSCs (GMSCs and OMSCs)}

GMSCs represent another population of adult dental stem cells isolated from the lamina propria of gingival tissues (53). Similar to other sources of MSCs, GMSCs possess multipotent differentiation and potent immunomodulatory/anti-inflammatory capacities, making them an easily accessible source of MSCs for TE and regenerative therapy of various craniofacial and noncraniofacial disorders $(120,121)$ (Table 4). Several lines of evidence have shown that transplantation of GMSC- 
derived CM, exosomes or GMSC-seeded scaffolds can stimulate periodontal repair/regeneration in periodontal defect models in rats $(122,123)$, dogs $(124)$, and minipigs (125). For instance, Yu et al. reported that transplanted GMSCs significantly enhanced the regeneration of the damaged periodontal tissue, including the alveolar bone, cementum and periodontal ligament (PDL) in Class III furcation defects of dogs. They found that GMSCs were able to differentiate into osteoblasts, cementoblasts, and PDL fibroblasts in vivo (124). These findings indicate that GMSCs represent a novel cell source for periodontal tissue. Fawzy El-Sayed et al. reported that GMSCs in conjunction with IL-1Ra-loaded HA-sECM significantly enhance periodontal regeneration in a minipig model (125).

In addition to the periodontal regenerative capacity, several preclinical studies have shown that GMSCs also have the potential to promote craniofacial bone regeneration in rodents (126-129) and minipigs (130). Most recently, a study has shown that GMSCs effectively delivered by a bioinspired adhesive hydrogel with tunable mechanical properties and biodegradability, can aggregate, form hydroxyapatite microparticles, and significantly promote craniofacial bone regeneration in rats (127). In a critical-sized maxillary alveolar defect model in nude rats, combination of predifferentiated osteogenic GMSCs, selfassembling hydrogel PuraMatrix ${ }^{\mathrm{TM}}(\mathrm{PM})$, and low doses of BMP2 accelerated alveolar bone regeneration when compared to cells or material alone. Predifferentiated osteogenic GMSCS are GMSCs induced with osteogenic medium resulting in increased expression of osteogenic surface markers such as CD10, CD92, and CD140b (128). An early study showed that implantation of GMSCs seeded on type I collagen gel significantly facilitate repair/ regeneration of the mandibular and calvarial defects at 2 months in rats postsurgical reconstruction (129). Most recently, Shi et al. reported that treatment with a TGF- $\beta$ signaling inhibitor, SB431542, increased the osteogenic differentiation potential of GMSCs and transplantation of autologous pig GMSCs pretreated with SB431542 significantly induce bone regeneration in critical-sized maxillofacial bone defects of minipigs (130).

In spite of their bone regenerative potentials, several lines of evidence have shown that transplantation of GMSCs can facilitate oral and craniofacial soft tissue repair/ regeneration, such as palatal wound $(70,133)$, gingival (134), and tongue myomucosal defects $(135,136)$, and facial nerve injuries $(137,138)$. For instance, Li et al. recently reported that transplantation of GMSCs from human fetal gingival tissue remarkably promotes repair/regeneration of gingival defects in a rat model (134). Using a criticalsized tongue defect model in rats, $\mathrm{Xu}$ (136) and Zhang (135) et al. reported that implantation of GMSC-loaded porcine small intestine submucosal extracellular matrix (SIS-ECM) membrane remarkably facilitated regeneration of tongue muscles and taste buds possibly by promoting endogenous muscle stem cell activation and suppressing fibrosis. Recently, Zhang et al. reported that implantation of 3D bioprinted scaffold free nerve structures with 3D-spheroids of GMSCs as the only cellular "bio-ink" (137) or implantation of collagen nerve conduits loaded with GMSC-induced NC stem-like cells (138) robustly promote axonal regeneration and functional recovery of transected facial nerves in rats. Altogether, these studies have underscored the potential application of GMSCs in TE and regenerative reconstruction of $\mathrm{OMF}$ tissue defects.

\section{Dental follicle progenitor cells (DFPCs)}

DFSCs represent a population of stem cells that contributes to the development of the periodontal ligament, cementum, and alveolar bone proper (139). Several preclinical studies have demonstrated the oral and craniofacial regenerative potentials of DFSCs in rodents (140$143)$ and large animal models $(108,141,144)$ (Table 5). A recent study showed that transplantation of DFSC cell sheets or DFSCs in combination with treated dentin matrix (TDM) induced periodontal-like tissue formation in dogs (141). In a canine periodontal defect model, Guo et al. reported that implantation of DFSC cell sheets robustly promoted the complete periodontal regeneration, including periodontal ligament-cementum complex and alveolar bone formation (108). In an early study, Zuolin et al. reported that transplantation of DFSC-beta-tricalcium phosphate ceramic (beta-TCP) complex promote the restoration of periodontal defects in beagle dogs (144). In addition, the regenerative potential of DFSCs on bone formation has also been demonstrated in alveolar and cranial bone defect models in rats (141-143). For example, implantation of DFSC-polycaprolactone (PCL) scaffold constructs significantly enhanced bone regeneration in critical-size skull defects in rats (142). In an alveolar bone defect model in rats, Nie et al. reported that implantation of bio-implants composed of Ad-BMP9-transfected rat DFSCs and coralline hydroxyapatite (CHA) scaffolds remarkably enhance alveolar bone regeneration (143). These findings 
Table 5 The potential application of DFSCs and SCAP in OMF tissue regeneration

\begin{tabular}{llccc}
\hline Cell Type & Scaffolds/other factors & Model & Object & References \\
\hline DFSC-CM & Conditioned medium & Pulpitis & Rat & Hong H et al. 2020, (140) \\
DFSC & $\begin{array}{l}\text { HA/ } \beta \text {-TCP particles/cell sheets/treated } \\
\text { dentin matrix }\end{array}$ & Calvarial defect/periodontal defect & Rat/dog & Yang H et al. 2019, (141) \\
DFSC/PDLSC & Cell sheets & Periodontal defect & Canine & Guo S et al. 2017, (108) \\
DFSC & B-TCP & Periodontal defects & Dog & Zuolin J et al. 2010, (144) \\
DFSC & Polycaprolactone scaffold & Cranial/skull defects & Rat & Rezai-Rad M et al. 2015, (142) \\
DFSC & Coralline hydroxyapatite & Alveolar bone defect & Rat & Nie L et al. 2017, (143) \\
SCAP & 3D-printed hydroxyapatite scaffolds & Pulp & Nude mice Hilkens P et al. 2017, (145) \\
SCAP-ExO & & Dentinogenesis & Nude mice Zhuang X et al. 2020, (146) \\
SCAP & & Periodontitis & Minipig Li G et al. 2018, (147) \\
SCAP & SFRP2 expressing & Periodontitis & Minipig Li G et al. 2020, (148) &
\end{tabular}

DFSC, dental follicle stem cell; SCAP, stem cells derived from apica papilla; OMF, oral and maxillofacial; CM, conditioned medium; PDLSC, periodontal ligament stem cell; HA, hydroxyapatite; $\beta$-TCP, $\beta$-tricalcium phosphate.

have demonstrated the potential application of DFSCs in regenerative reconstruction of OMF tissues.

\section{SCAP}

SCAP represent a unique subpopulation of dental stem cells from immature permanent teeth (54) and have been shown to be another type of dental MSCs with potential application in regenerative endodontic procedures and TE/RM in general $(149,150)$ (Table 5). When 3D-printed hydroxyapatite scaffolds containing DPSCs and/or SCAPs were subcutaneously transplanted into immunocompromised mice, vascularized pulp-like tissue as well as mineralized tissue formed at 12 -weeks posttransplantation, demonstrating angiogenic and regenerative potential (145). Li et al. recently reported that local injection of SCAPs promote periodontal complex regeneration in the swine periodontitis model $(147,148)$. Altogether, these findings support the potential application of SCAPs in regenerative reconstruction of $\mathrm{OMF}$ tissues.

\section{Application of dental MSC-EVs in OMF tissue regeneration}

MSC-EVs serve a myriad of biological functions and possess immense therapeutic potential $(44,48)$. Accumulating evidence has shown the potential use of dental MSC-derived EVs as cell-free agents in TE and regenerative therapy in the dental and craniofacial reconstruction $(151,152)$ (Figure 2). Administration of CM derived from different types of dental-MSCs displayed potent regenerative/ therapeutic potentials in oral and craniofacial defect models. For instance, SHED-CM has been shown to induce rat superior laryngeal nerve (SLN) regeneration (102). PDLSC-CM could stimulate bone regeneration in calvarial defects of mice (114) and periodontal regeneration in rats (105). GMSC-CM and DFSC-CM significantly promote rat periodontal (122) and pulp-dentin (140) regeneration, respectively. Additionally, it has been shown that GMSC-EVs loaded with a poly-(lactide) (3D-PLA) facilitated calvarial bone regeneration in rats (153).

In recent years, surmounting evidence has implicated the regenerative/therapeutic potentials of EVs released by different types of dental-MSCs (Table 5). Swanson et al. reported that application of DPSC-EVs with a controlled-release by PLGA and poly(ethylene glycol) (PEG) remarkably increase calvarial bone regeneration in mice (84). DPSC-EVs promote dentin-pulp regeneration following injection into the exposed pulp tissue of rat incisors (154). In a minipig model of pulp injury, Wen et al. reported that treatment with DPSC-EVs mixed with treated dentin matrix (TDM) proteins significantly promote pulp-dentin complex repair/regeneration (155). Regarding the regenerative/therapeutic potential of GMSC-EVs in OMF defects, Kou et al. showed that local 
injection of GMSC-EVs significantly facilitated palatal wound healing in mice (70). Most recently, it has been reported that EVs from TNF- $\alpha$-preconditioned GMSCs displayed potent regenerative/therapeutic potentials in periodontal regeneration of mice (123). In a criticalsized tongue defect model in rats, Zhang et al. showed that transplantation of SIS-ECM loaded with GMSCEVs significantly promoted taste bud regeneration (135). Furthermore, implantation of GMSC-EVs loaded with 3D printing biomaterial, poly(lactide) (3D-PLA), display bone regenerative capacity in calvarial defects in rats $(131,132)$. In a nude mice model, subcutaneous transplantation of BMSCs mixed with SCAP-Exo showed significantly increased ectopic formation of dentine-pulp like structures, suggesting the specific dentinogenetic potential of SCAP-EVs (146). Lastly, Shi et al. has recently reported that application of hydrogel loaded with EVs derived from LPS-preconditioned DFSCs remarkably prevented bone loss and engendered new bone formation in experimental rat periodontitis model (156). Taken together, these results demonstrate compelling evidence for the use of CM and/ or purified EVs derived from dental-MSCs as alternative cell-free products for $\mathrm{TE}$ and regenerative reconstruction of OMF tissue defects.

\section{Challenges of MSC-based regenerative therapies}

Despite a favorable safety profile and numerous studies demonstrating its effectiveness in preclinical studies, in general, there has been limited success of application of MSCs and MSC-EVs in humans $(41,42)$. The cause of this translational barrier is due to multiple intrinsic and extrinsic factors that can contribute to the heterogeneity in the potency of MSC products. These factors include differences in donors (e.g., their age, health status, tissue origins), the methods for MSC preparation (e.g., the isolation, ex vivo culture/expansion, and storage) and administration (e.g., the route, dosage, frequency, and the carrier/vehicle) as well as the health/disease status of the recipients (42). In term of MSC-based TE, the difference in the type of biomaterials or scaffolds, TE technologies, small molecules and/growth factors may also significantly affect the potency and clinical outcomes of MSC-based TE products (157). Even though a general safety profile has been well recognized for MSC-based therapy, there are still some related potential risks, side effects or complications, such as acute/immediate responses to MSC administration, infection, thrombotic/embolic (158), and ectopic calcification (159), heterotopic ossification (160), or tumor-like tissue mass formation (161). Therefore, more rigorous studies are warranted to evaluate the therapeutic potency as well as potential short-term and long-term complications related to MSC-based regenerative therapy, including MSC-based reconstruction and rehabilitation of OMF defects.

\section{Summary}

Significant progress has been made in TE and MSCbased regenerative therapy across many fields of medicine, including oral \& maxillofacial reconstruction and facial cosmetics $(22,23)$. To date, there have been over 1,200 registered and 300 completed clinical trials using MSCs to treat a large spectrum of pathological conditions (https:// www.clinicaltrials.gov/) (42), including MSCs used in the management of craniofacial injuries or abnormalities (https://www.clinicaltrials.gov). In addition, MSC-derived $\mathrm{EVs}$, a cell-free product, implemented in many preclinical models of diseases, have demonstrated therapeutic capacity in the regeneration of OMF tissues (Table 6). Of note, however, MSCs and MSC-EV products when applied to humans do not show the same therapeutic effect. This is largely attributed to the heterogeneity in the potency and property of MSCs owing to differing intrinsic factors, such as the tissue source and donor characteristics, as well as extrinsic factors, such as methods and technologies involved in tissue harvesting, cell isolation/expansion, TE, and product storage/administration (42). It is thus essential to establish standard operating procedures (SOP) for all the steps in the production of dental MSCs, MSCEVs, or MSC-based TE constructs with cGMP qualities (15). Generation of MSC-EVs presents additional technical and biological challenges $(162,163)$. Specifically, cell isolation methods significantly affect the purity and yield of EVs (164), while the source and status of cells affect the production and cargo components of MSC-EVs $(162,163)$. To advance the clinical application of MSC$\mathrm{EVs}$ in OMF tissue regeneration and reconstruction, it is critical to experimentally optimize their production in future studies. 
Table 6 Potential application of dental-MSC-derived EVs in OMF tissue regeneration

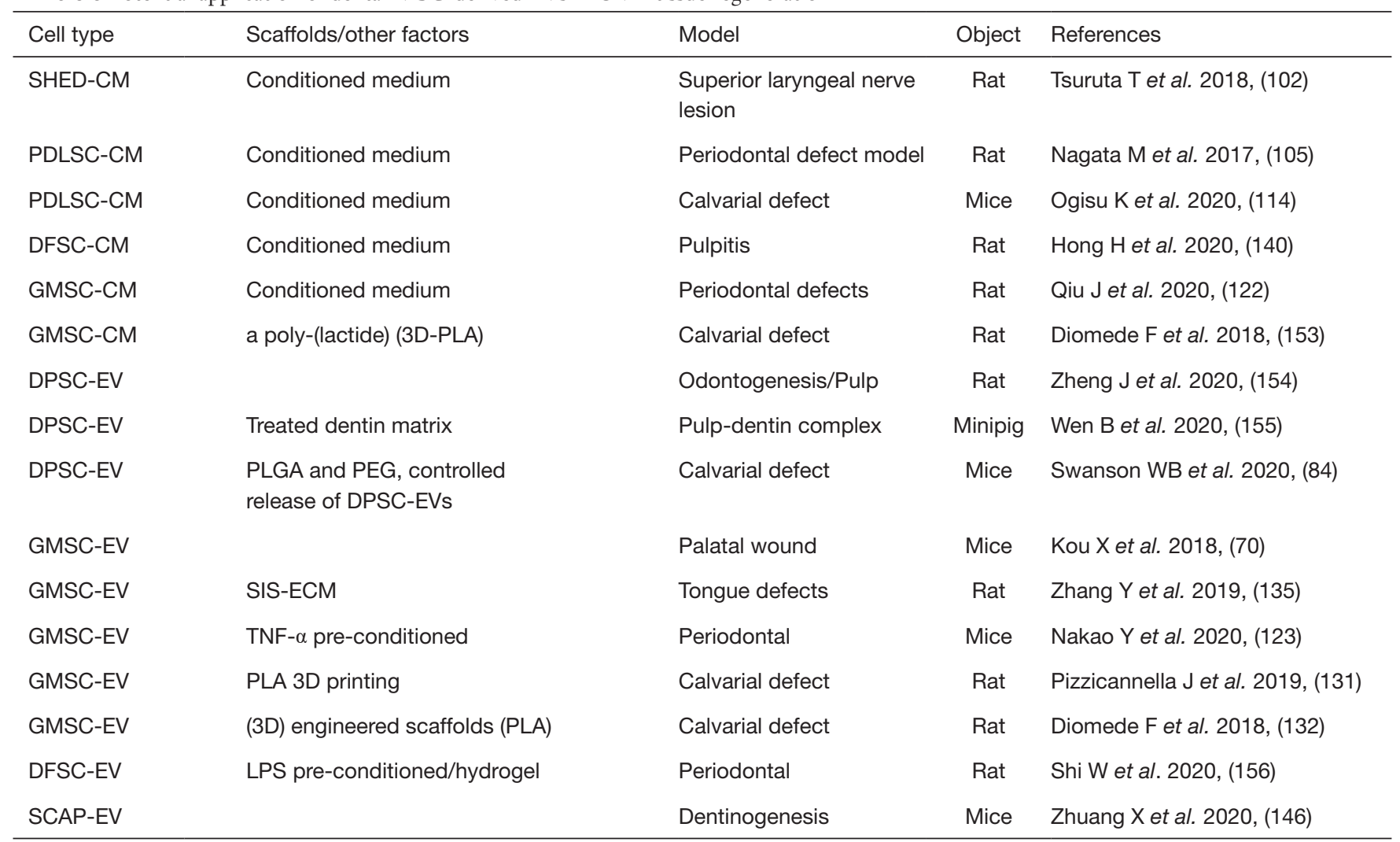

SHED, stem cells from human exfoliated deciduous teeth; MSC, mesenchymal stem cell; EV, extracellular vesicle; OMF, oral and maxillofacial; CM, conditioned medium; PLGA, Poly(lactic-co-glycolic acid); PEG, poly(ethylene glycol); SIS-ECM, small intestinal submucosa extracellular matrix; LPS, lipopolysaccharide.

\section{Acknowledgments}

Funding: This work was supported by the National Institute of Dental and Craniofacial Research (NIH/NIDCR) No. R21DE029926-01 (A. Le), the Schoenleber funding support (A. Le and Q. Zhang), the Project Funding from Center for Human Appearance (CHA) at UPenn (Q. Zhang), OsteoScience Foundation-Peter Geistlich Research Awards (R. Shanti, Q. Zhang), Oral \& Maxillofacial Surgery Foundation (OMSF)-Research Support Grant (R. Shanti, Q. Zhang), OsteoScience Foundation-Resident Research Awards (P. He).

\section{Footnote}

Provenance and Peer Review: This article was commissioned by the Guest Editor (Sung-Kiang Chuang) for the series "Clinical Outcomes and Innovations in Oral and Maxillofacial Surgery" published in Frontiers of Oral and Maxillofacial Medicine. The article has undergone external peer review.
Reporting Checklist: The authors have completed the Narrative Review reporting checklist. Available at https:// fomm.amegroups.com/article/view/10.21037/fomm-21-10/ rc

Conflicts of Interest: All authors have completed the ICMJE uniform disclosure form (available at https://fomm.amegroups. com/article/view/10.21037/fomm-21-10/coif). The series "Clinical Outcomes and Innovations in Oral and Maxillofacial Surgery" was commissioned by the editorial office without any funding or sponsorship. This work was supported by the National Institute of Dental and Craniofacial Research (NIH/ NIDCR) R21DE029926-01 (A. Le), the Schoenleber funding support (A. Le and Q. Zhang), the Project Funding from Center for Human Appearance (CHA) at UPenn (Q. Zhang), OsteoScience Foundation-Peter Geistlich Research Awards (R. Shanti, Q. Zhang), Oral \& Maxillofacial Surgery Foundation (OMSF)-Research Support Grant (R. Shanti, Q. Zhang), OsteoScience Foundation-Resident Research Awards (P. He). 
The authors have no other conflicts of interest to declare.

Ethical Statement: The authors are accountable for all aspects of the work in ensuring that questions related to the accuracy or integrity of any part of the work are appropriately investigated and resolved.

Open Access Statement: This is an Open Access article distributed in accordance with the Creative Commons Attribution-NonCommercial-NoDerivs 4.0 International License (CC BY-NC-ND 4.0), which permits the noncommercial replication and distribution of the article with the strict proviso that no changes or edits are made and the original work is properly cited (including links to both the formal publication through the relevant DOI and the license). See: https://creativecommons.org/licenses/by-nc-nd/4.0/.

\section{References}

1. Markiewicz MR, Gelesko S, Bell RB. Zygoma reconstruction. Oral Maxillofac Surg Clin North Am 2013;25:167-201.

2. Lenox ND, Kim DD. Maxillary reconstruction. Oral Maxillofac Surg Clin North Am 2013;25:215-22.

3. Fernandes RP, Yetzer JG. Reconstruction of acquired oromandibular defects. Oral Maxillofac Surg Clin North Am 2013;25:241-9.

4. Vega LG, González-García R, Louis PJ. Reconstruction of acquired temporomandibular joint defects. Oral Maxillofac Surg Clin North Am 2013;25:251-69.

5. Twigg SR, Wilkie AO. New insights into craniofacial malformations. Hum Mol Genet 2015;24:R50-9.

6. Hunter C, Januszyk M, Wan DC, et al. Systematic Reviews in Craniofacial Trauma-Strengths and Weaknesses. Ann Plast Surg 2016;77:363-8.

7. Khokha MK, Liu KJ, Wallingford JB. Challenges and opportunities at the interface of birth defects, human genetics and developmental biology. Development 2020;147:dev197871.

8. Nyberg EL, Farris AL, Hung BP, et al. 3D-Printing Technologies for Craniofacial Rehabilitation, Reconstruction, and Regeneration. Ann Biomed Eng 2017;45:45-57.

9. Zhang W, Yelick PC. Craniofacial Tissue Engineering. Cold Spring Harb Perspect Med 2018;8:a025775.

10. Shanti RM, O'Malley BW Jr. Surgical Management of Oral Cancer. Dent Clin North Am 2018;62:77-86.

11. Valdez JA, Brennan MT. Impact of Oral Cancer on Quality of Life. Dent Clin North Am 2018;62:143-54.

12. Streubel SO, Mirsky DM. Craniomaxillofacial Trauma. Facial Plast Surg Clin North Am 2016;24:605-17.

13. Petrovic I, Rosen EB, Matros E, et al. Oral rehabilitation of the cancer patient: A formidable challenge. J Surg Oncol 2018;117:1729-35.

14. Barclay CW, Foster EC, Taylor CL. Restorative aspects of oral cancer reconstruction. Br Dent J 2018;225:848-54.

15. Zhang QZ, Chen C, Chang MB, et al. Oral Rehabilitation of Patients Sustaining Orofacial Injuries: The UPenn Initiative. Adv Dent Res 2019;30:50-6.

16. Kumar BP, Venkatesh V, Kumar KA, et al. Mandibular Reconstruction: Overview. J Maxillofac Oral Surg 2016;15:425-41.

17. Minatel L, Marcela de Luna Gomes J, Aparecido Araújo Lemos C, et al. Influence of vomer flap on craniofacial growth in patients with cleft lip and palate: A systematic review. J Craniomaxillofac Surg 2019;47:902-8.

18. van Gijn DR, D'Souza J, King W, et al. Free Flap Head and Neck Reconstruction with an Emphasis on Postoperative Care. Facial Plast Surg 2018;34:597-604.

19. Boehm KS, Al-Taha M, Morzycki A, et al. Donor Site Morbidities of Iliac Crest Bone Graft in Craniofacial Surgery: A Systematic Review. Ann Plast Surg 2019;83:352-8.

20. Broyles JM, Abt NB, Shridharani SM, et al. The fusion of craniofacial reconstruction and microsurgery: a functional and aesthetic approach. Plast Reconstr Surg 2014;134:760-9.

21. Armstrong JPK, Keane TJ, Roques AC, et al. A blueprint for translational regenerative medicine. Sci Transl Med 2020;12:eaaz2253.

22. Borrelli MR, Hu MS, Longaker MT, et al. Tissue Engineering and Regenerative Medicine in Craniofacial Reconstruction and Facial Aesthetics. J Craniofac Surg 2020;31:15-27.

23. Pourlak T, Pourlak T, Ghodrati M, et al. Usage of stem cells in oral and maxillofacial region. J Stomatol Oral Maxillofac Surg 2020. [Epub ahead of print]. doi: 10.1016/ j.jormas.2020.10.003.

24. Matichescu A, Ardelean LC, Rusu LC, et al. Advanced Biomaterials and Techniques for Oral Tissue Engineering and Regeneration-A Review. Materials (Basel) 2020;13:5303.

25. Shanti RM, Li WJ, Nesti LJ, et al. Adult mesenchymal stem cells: biological properties, characteristics, and applications in maxillofacial surgery. J Oral Maxillofac Surg 2007;65:1640-7. 
26. Friedenstein AJ, Chailakhjan RK, Lalykina KS. The development of fibroblast colonies in monolayer cultures of guinea-pig bone marrow and spleen cells. Cell Tissue Kinet 1970;3:393-403.

27. Castro-Malaspina H, Gay RE, Resnick G, et al. Characterization of human bone marrow fibroblast colony-forming cells (CFU-F) and their progeny. Blood 1980;56:289-301.

28. Dominici M, Le Blanc K, Mueller I, et al. Minimal criteria for defining multipotent mesenchymal stromal cells. The International Society for Cellular Therapy position statement. Cytotherapy 2006;8:315-7.

29. Aust L, Devlin B, Foster SJ, et al. Yield of human adiposederived adult stem cells from liposuction aspirates. Cytotherapy 2004;6:7-14.

30. Klein D. Lung Multipotent Stem Cells of Mesenchymal Nature: Cellular Basis, Clinical Relevance, and Implications for Stem Cell Therapy. Antioxid Redox Signal 2021;35:204-16.

31. Yates CC, Rodrigues M, Nuschke A, et al. Multipotent stromal cells/mesenchymal stem cells and fibroblasts combine to minimize skin hypertrophic scarring. Stem Cell Res Ther 2017;8:193.

32. He Q, Wan C, Li G. Concise review: multipotent mesenchymal stromal cells in blood. Stem Cells 2007;25:69-77.

33. Fan J, Varshney RR, Ren L, et al. Synovium-derived mesenchymal stem cells: a new cell source for musculoskeletal regeneration. Tissue Eng Part B Rev 2009; 15:75-86.

34. Čamernik K, Marc J, Zupan J. Human Skeletal MuscleDerived Mesenchymal Stem/Stromal Cell Isolation and Growth Kinetics Analysis. Methods Mol Biol 2019;2045:119-29.

35. In 't Anker PS, Scherjon SA, Kleijburg-van der Keur C, et al. Isolation of mesenchymal stem cells of fetal or maternal origin from human placenta. Stem Cells 2004;22:1338-45.

36. Xie Q, Liu R, Jiang J, et al. What is the impact of human umbilical cord mesenchymal stem cell transplantation on clinical treatment? Stem Cell Res Ther 2020;11:519.

37. Gan L, Liu Y, Cui D, et al. Dental Tissue-Derived Human Mesenchymal Stem Cells and Their Potential in Therapeutic Application. Stem Cells Int 2020;2020:8864572.

38. Tatullo M, Marrelli M, Paduano F. The regenerative medicine in oral and maxillofacial surgery: the most important innovations in the clinical application of mesenchymal stem cells. Int J Med Sci 2015;12:72-7.

39. El Agha E, Kramann R, Schneider RK, et al. Mesenchymal Stem Cells in Fibrotic Disease. Cell Stem Cell 2017;21:166-77.

40. Forbes SJ, Rosenthal N. Preparing the ground for tissue regeneration: from mechanism to therapy. Nat Med 2014;20:857-69.

41. Martin I, Galipeau J, Kessler C, et al. Challenges for mesenchymal stromal cell therapies. Sci Transl Med 2019;11:eaat2189.

42. Levy O, Kuai R, Siren EMJ, et al. Shattering barriers toward clinically meaningful MSC therapies. Sci Adv 2020;6:eaba6884.

43. Shi Y, Wang Y, Li Q, et al. Immunoregulatory mechanisms of mesenchymal stem and stromal cells in inflammatory diseases. Nat Rev Nephrol 2018;14:493-507.

44. Fu Y, Karbaat L, Wu L, et al. Trophic Effects of Mesenchymal Stem Cells in Tissue Regeneration. Tissue Eng Part B Rev 2017;23:515-28.

45. Viswanathan S, Shi Y, Galipeau J, et al. Mesenchymal stem versus stromal cells: International Society for Cell \& Gene Therapy (ISCT®) Mesenchymal Stromal Cell committee position statement on nomenclature. Cytotherapy 2019;21:1019-24.

46. Kalluri R, LeBleu VS. The biology, function, and biomedical applications of exosomes. Science 2020;367:eaau6977.

47. Cocucci E, Meldolesi J. Ectosomes and exosomes: shedding the confusion between extracellular vesicles. Trends Cell Biol 2015;25:364-72.

48. Tsiapalis D, O'Driscoll L. Mesenchymal Stem Cell Derived Extracellular Vesicles for Tissue Engineering and Regenerative Medicine Applications. Cells 2020;9:991.

49. Cooper LF, Ravindran S, Huang CC, et al. A Role for Exosomes in Craniofacial Tissue Engineering and Regeneration. Front Physiol 2019;10:1569.

50. Gronthos S, Mankani M, Brahim J, et al. Postnatal human dental pulp stem cells (DPSCs) in vitro and in vivo. Proc Natl Acad Sci U S A 2000;97:13625-30.

51. Miura M, Gronthos S, Zhao M, et al. SHED: stem cells from human exfoliated deciduous teeth. Proc Natl Acad Sci U S A 2003;100:5807-12.

52. Seo BM, Miura M, Gronthos S, et al. Investigation of multipotent postnatal stem cells from human periodontal ligament. Lancet 2004;364:149-55.

53. Zhang Q, Shi S, Liu Y, et al. Mesenchymal stem cells derived from human gingiva are capable of immunomodulatory functions and ameliorate 
inflammation-related tissue destruction in experimental colitis. J Immunol 2009;183:7787-98.

54. Sonoyama W, Liu Y, Yamaza T, et al. Characterization of the apical papilla and its residing stem cells from human immature permanent teeth: a pilot study. J Endod 2008;34:166-71.

55. Yao S, Pan F, Prpic V, et al. Differentiation of stem cells in the dental follicle. J Dent Res 2008;87:767-71.

56. Guven EP, Yalvac ME, Sahin F, et al. Effect of dental materials calcium hydroxide-containing cement, mineral trioxide aggregate, and enamel matrix derivative on proliferation and differentiation of human tooth germ stem cells. J Endod 2011;37:650-6.

57. Andrukhov O, Behm C, Blufstein A, et al. Immunomodulatory properties of dental tissue-derived mesenchymal stem cells: Implication in disease and tissue regeneration. World J Stem Cells 2019;11:604-17.

58. Liu J, Yu F, Sun Y, et al. Concise reviews: Characteristics and potential applications of human dental tissue-derived mesenchymal stem cells. Stem Cells 2015;33:627-38.

59. Perera SN, Kerosuo L. On the road again: Establishment and maintenance of stemness in the neural crest from embryo to adulthood. Stem Cells 2021;39:7-25.

60. Etchevers HC, Dupin E, Le Douarin NM. The diverse neural crest: from embryology to human pathology. Development 2019;146:dev169821.

61. Solis-Castro OO, Boissonade FM, Rivolta MN. Establishment and neural differentiation of neural crestderived stem cells from human dental pulp in serum-free conditions. Stem Cells Transl Med 2020;9:1462-76.

62. Marynka-Kalmani K, Treves S, Yafee M, et al. The lamina propria of adult human oral mucosa harbors a novel stem cell population. Stem Cells 2010;28:984-95.

63. Abe S, Yamaguchi S, Sato Y, et al. Sphere-Derived Multipotent Progenitor Cells Obtained From Human Oral Mucosa Are Enriched in Neural Crest Cells. Stem Cells Transl Med 2016;5:117-28.

64. Fournier BP, Loison-Robert LS, Ferré FC, et al. Characterisation of human gingival neural crest-derived stem cells in monolayer and neurosphere cultures. Eur Cell Mater 2016;31:40-58.

65. Davies LC, Locke M, Webb RD, et al. A multipotent neural crest-derived progenitor cell population is resident within the oral mucosa lamina propria. Stem Cells Dev 2010;19:819-30.

66. Gosau M, Götz W, Felthaus O, et al. Comparison of the differentiation potential of neural crest derived progenitor cells from apical papilla (dNC-PCs) and stem cells from exfoliated deciduous teeth (SHED) into mineralising cells. Arch Oral Biol 2013;58:699-706.

67. Lima RL, Holanda-Afonso RC, Moura-Neto V, et al. Human dental follicle cells express embryonic, mesenchymal and neural stem cells markers. Arch Oral Biol 2017;73:121-8.

68. Pisciotta A, Bertoni L, Vallarola A, et al. Neural crest derived stem cells from dental pulp and tooth-associated stem cells for peripheral nerve regeneration. Neural Regen Res 2020;15:373-81.

69. Xu X, Chen C, Akiyama K, et al. Gingivae contain neuralcrest- and mesoderm-derived mesenchymal stem cells. J Dent Res 2013;92:825-32.

70. Kou X, Xu X, Chen C, et al. The Fas/Fap-1/Cav-1 complex regulates IL-1RA secretion in mesenchymal stem cells to accelerate wound healing. Sci Transl Med 2018;10:eaai8524.

71. Shi HZ, Zeng JC, Shi SH, et al. Extracellular Vesicles of GMSCs Alleviate Aging-Related Cell Senescence. J Dent Res 2021;100:283-92.

72. Zhou H, Li X, Yin Y, et al. The proangiogenic effects of extracellular vesicles secreted by dental pulp stem cells derived from periodontally compromised teeth. Stem Cell Res Ther 2020;11:110.

73. Cao Y, Vacanti JP, Paige KT, et al. Transplantation of chondrocytes utilizing a polymer-cell construct to produce tissue-engineered cartilage in the shape of a human ear. Plast Reconstr Surg 1997;100:297-302; discussion 303-4.

74. Sui B, Wu D, Xiang L, et al. Dental Pulp Stem Cells: From Discovery to Clinical Application. J Endod 2020;46:S46-55.

75. Shi X, Mao J, Liu Y. Pulp stem cells derived from human permanent and deciduous teeth: Biological characteristics and therapeutic applications. Stem Cells Transl Med 2020;9:445-64.

76. Aghali A, Arman HE. Photoencapsulated-mesenchymal stromal cells in biodegradable thiol-acrylate hydrogels enhance regeneration of craniofacial bone tissue defects. Regen Med 2020;15:2115-27.

77. Zhang W, Saxena S, Fakhrzadeh A, et al. Use of Human Dental Pulp and Endothelial Cell Seeded TyrosineDerived Polycarbonate Scaffolds for Robust in vivo Alveolar Jaw Bone Regeneration. Front Bioeng Biotechnol 2020;8:796.

78. Gutiérrez-Quintero JG, Durán Riveros JY, Martínez Valbuena CA, et al. Critical-sized mandibular defect reconstruction using human dental pulp stem cells in a xenograft model-clinical, radiological, and histological 
evaluation. Oral Maxillofac Surg 2020;24:485-93.

79. Alkaisi A, Ismail AR, Mutum SS, et al. Transplantation of human dental pulp stem cells: enhance bone consolidation in mandibular distraction osteogenesis. J Oral Maxillofac Surg 2013;71:1758 e1-13.

80. Zhang W, Zhang Z, Chen S, et al. Mandibular Jaw Bone Regeneration Using Human Dental Cell-Seeded TyrosineDerived Polycarbonate Scaffolds. Tissue Eng Part A 2016;22:985-93.

81. Riccio M, Maraldi T, Pisciotta A, et al. Fibroin scaffold repairs critical-size bone defects in vivo supported by human amniotic fluid and dental pulp stem cells. Tissue Eng Part A 2012;18:1006-13.

82. Jahanbin A, Rashed R, Alamdari DH, et al. Success of Maxillary Alveolar Defect Repair in Rats Using Osteoblast-Differentiated Human Deciduous Dental Pulp Stem Cells. J Oral Maxillofac Surg 2016;74:829.e1-9.

83. Ghavimi MA, Bani Shahabadi A, Jarolmasjed S, et al. Nanofibrous asymmetric collagen/curcumin membrane containing aspirin-loaded PLGA nanoparticles for guided bone regeneration. Sci Rep 2020;10:18200.

84. Swanson WB, Zhang Z, Xiu K, et al. Scaffolds with controlled release of pro-mineralization exosomes to promote craniofacial bone healing without cell transplantation. Acta Biomater 2020;118:215-32.

85. Fujii Y, Kawase-Koga Y, Hojo H, et al. Bone regeneration by human dental pulp stem cells using a helioxanthin derivative and cell-sheet technology. Stem Cell Res Ther 2018;9:24.

86. Collignon AM, Castillo-Dali G, Gomez E, et al. Mouse Wnt1-CRE-RosaTomato Dental Pulp Stem Cells Directly Contribute to the Calvarial Bone Regeneration Process. Stem Cells 2019;37:701-11.

87. Novais A, Lesieur J, Sadoine J, et al. Priming Dental Pulp Stem Cells from Human Exfoliated Deciduous Teeth with Fibroblast Growth Factor-2 Enhances Mineralization Within Tissue-Engineered Constructs Implanted in Craniofacial Bone Defects. Stem Cells Transl Med 2019;8:844-57.

88. Nakajima K, Kunimatsu R, Ando K, et al. Comparison of the bone regeneration ability between stem cells from human exfoliated deciduous teeth, human dental pulp stem cells and human bone marrow mesenchymal stem cells. Biochem Biophys Res Commun 2018;497:876-82.

89. Annibali S, Bellavia D, Ottolenghi L, et al. MicroCT and PET analysis of bone regeneration induced by biodegradable scaffolds as carriers for dental pulp stem cells in a rat model of calvarial "critical size" defect:
Preliminary data. J Biomed Mater Res B Appl Biomater 2014;102:815-25.

90. Petridis X, Diamanti E, Trigas GCh, et al. Bone regeneration in critical-size calvarial defects using human dental pulp cells in an extracellular matrix-based scaffold. J Craniomaxillofac Surg 2015;43:483-90.

91. Asutay F, Polat S, Gül M, et al. The effects of dental pulp stem cells on bone regeneration in rat calvarial defect model: micro-computed tomography and histomorphometric analysis. Arch Oral Biol 2015;60:1729-35.

92. Chamieh F, Collignon AM, Coyac BR, et al. Accelerated craniofacial bone regeneration through dense collagen gel scaffolds seeded with dental pulp stem cells. Sci Rep 2016;6:38814.

93. Wongsupa N, Nuntanaranont T, Kamolmattayakul S, et al. Assessment of bone regeneration of a tissue-engineered bone complex using human dental pulp stem cells/ poly( $\varepsilon$-caprolactone)-biphasic calcium phosphate scaffold constructs in rabbit calvarial defects. J Mater Sci Mater Med 2017;28:77.

94. Çolpak HA, Gönen ZB, Özdamar S, et al. Vertical ridge augmentation using guided bone regeneration procedure and dental pulp derived mesenchymal stem cells with simultaneous dental implant placement: A histologic study in a sheep model. J Stomatol Oral Maxillofac Surg 2019;120:216-23.

95. Ito K, Yamada Y, Nakamura S, et al. Osteogenic potential of effective bone engineering using dental pulp stem cells, bone marrow stem cells, and periosteal cells for osseointegration of dental implants. Int J Oral Maxillofac Implants 2011;26:947-54.

96. Talaat W, Aryal Ac S, Al Kawas S, et al. Nanoscale Thermosensitive Hydrogel Scaffolds Promote the Chondrogenic Differentiation of Dental Pulp Stem and Progenitor Cells: A Minimally Invasive Approach for Cartilage Regeneration. Int J Nanomedicine 2020;15:7775-89.

97. Li Y, Nan X, Zhong TY, et al. Treatment of Periodontal Bone Defects with Stem Cells from Inflammatory Dental Pulp Tissues in Miniature Swine. Tissue Eng Regen Med 2019;16:191-200.

98. Hu J, Cao Y, Xie Y, et al. Periodontal regeneration in swine after cell injection and cell sheet transplantation of human dental pulp stem cells following good manufacturing practice. Stem Cell Res Ther 2016;7:130.

99. Li Y, Zhao S, Nan X, et al. Repair of human periodontal bone defects by autologous grafting stem cells derived 
from inflammatory dental pulp tissues. Stem Cell Res Ther 2016;7:141.

100.Ahmed MN, Shi D, Dailey MT, et al. Dental Pulp Cell Sheets Enhance Facial Nerve Regeneration via Local Neurotrophic Factor Delivery. Tissue Eng Part A 2020. [Epub ahead of print]. doi: 10.1089/ten.TEA.2020.0265.

101. Sasaki R, Aoki S, Yamato M, et al. PLGA artificial nerve conduits with dental pulp cells promote facial nerve regeneration. J Tissue Eng Regen Med 2011;5:823-30.

102. Tsuruta T, Sakai K, Watanabe J, et al. Dental pulp-derived stem cell conditioned medium to regenerate peripheral nerves in a novel animal model of dysphagia. PLoS One 2018;13:e0208938.

103. Raju R, Oshima M, Inoue M, et al. Three-dimensional periodontal tissue regeneration using a bone-ligament complex cell sheet. Sci Rep 2020;10:1656.

104.Liu J, Chen B, Bao J, et al. Macrophage polarization in periodontal ligament stem cells enhanced periodontal regeneration. Stem Cell Res Ther 2019;10:320.

105. Nagata M, Iwasaki K, Akazawa K, et al. Conditioned Medium from Periodontal Ligament Stem Cells Enhances Periodontal Regeneration. Tissue Eng Part A 2017;23:367-77.

106.Han J, Menicanin D, Marino V, et al. Assessment of the regenerative potential of allogeneic periodontal ligament stem cells in a rodent periodontal defect model. J Periodontal Res 2014;49:333-45.

107.Lin Y, Gallucci GO, Buser D, et al. Bioengineered periodontal tissue formed on titanium dental implants. J Dent Res 2011;90:251-6.

108. Guo S, Kang J, Ji B, et al. Periodontal-Derived Mesenchymal Cell Sheets Promote Periodontal Regeneration in Inflammatory Microenvironment. Tissue Eng Part A 2017;23:585-96.

109. Basan T, Welly D, Kriebel K, et al. Enhanced periodontal regeneration using collagen, stem cells or growth factors. Front Biosci (Schol Ed) 2017;9:180-93.

110.Park JY, Jeon SH, Choung PH. Efficacy of periodontal stem cell transplantation in the treatment of advanced periodontitis. Cell Transplant 2011;20:271-85.

111. Iwata T, Yamato M, Washio K, et al. Periodontal regeneration with autologous periodontal ligament-derived cell sheets - A safety and efficacy study in ten patients. Regen Ther 2018;9:38-44.

112.Yu BH, Zhou Q, Wang ZL. Comparison of tissueengineered bone from different stem cell sources for maxillary sinus floor augmentation: a study in a canine model. J Oral Maxillofac Surg 2014;72:1084-92.
113. Moshaverinia A, Chen C, Xu X, et al. Bone regeneration potential of stem cells derived from periodontal ligament or gingival tissue sources encapsulated in RGD-modified alginate scaffold. Tissue Eng Part A 2014;20:611-21.

114. Ogisu K, Fujio M, Tsuchiya S, et al. Conditioned media from mesenchymal stromal cells and periodontal ligament fibroblasts under cyclic stretch stimulation promote bone healing in mouse calvarial defects. Cytotherapy 2020;22:543-51.

115. Tour G, Wendel M, Moll G, et al. Bone repair using periodontal ligament progenitor cell-seeded constructs. J Dent Res 2012;91:789-94.

116. Ge S, Zhao N, Wang L, et al. Bone repair by periodontal ligament stem cellseeded nanohydroxyapatite-chitosan scaffold. Int J Nanomedicine 2012;7:5405-14.

117. Kadkhoda Z, Safarpour A, Azmoodeh F, et al. Histopathological Comparison between Bone Marrowand Periodontium-derived Stem Cells for Bone Regeneration in Rabbit Calvaria. Int J Organ Transplant Med 2016;7:9-18.

118. Tomokiyo A, Wada N, Maeda H. Periodontal Ligament Stem Cells: Regenerative Potency in Periodontium. Stem Cells Dev 2019;28:974-85.

119.Xu XY, Li X, Wang J, et al. Concise Review: Periodontal Tissue Regeneration Using Stem Cells: Strategies and Translational Considerations. Stem Cells Transl Med 2019;8:392-403.

120.Zhang QZ, Nguyen AL, Yu WH, et al. Human oral mucosa and gingiva: a unique reservoir for mesenchymal stem cells. J Dent Res 2012;91:1011-8.

121. Gao X, Cao Z. Gingiva-derived Mesenchymal Stem Cells and Their Potential Applications in Oral and Maxillofacial Diseases. Curr Stem Cell Res Ther 2020;15:43-53.

122. Qiu J, Wang X, Zhou H, et al. Enhancement of periodontal tissue regeneration by conditioned media from gingiva-derived or periodontal ligament-derived mesenchymal stem cells: a comparative study in rats. Stem Cell Res Ther 2020;11:42.

123. Nakao Y, Fukuda T, Zhang Q, et al. Exosomes from TNF$\alpha$-treated human gingiva-derived MSCs enhance M2 macrophage polarization and inhibit periodontal bone loss. Acta Biomater 2021;122:306-24.

124.Yu X, Ge S, Chen S, et al. Human gingiva-derived mesenchymal stromal cells contribute to periodontal regeneration in beagle dogs. Cells Tissues Organs 2013;198:428-37.

125.Fawzy El-Sayed KM, Mekhemar MK, Beck-Broichsitter $\mathrm{BE}$, et al. Periodontal regeneration employing gingival 
margin-derived stem/progenitor cells in conjunction with IL-1ra-hydrogel synthetic extracellular matrix. J Clin Periodontol 2015;42:448-57.

126.Xu QC, Wang ZG, Ji QX, et al. Systemically transplanted human gingiva-derived mesenchymal stem cells contributing to bone tissue regeneration. Int J Clin Exp Pathol 2014;7:4922-9.

127.Hasani-Sadrabadi MM, Sarrion P, Pouraghaei S, et al. An engineered cell-laden adhesive hydrogel promotes craniofacial bone tissue regeneration in rats. Sci Transl Med 2020;12:eaay6853.

128. Kandalam U, Kawai T, Ravindran G, et al. Predifferentiated Gingival Stem Cell-Induced Bone Regeneration in Rat Alveolar Bone Defect Model. Tissue Eng Part A 2021;27:424-36.

129. Wang F, Yu M, Yan X, et al. Gingiva-derived mesenchymal stem cell-mediated therapeutic approach for bone tissue regeneration. Stem Cells Dev 2011;20:2093-102.

130.Shi A, Heinayati A, Bao D, et al. Small molecule inhibitor of TGF- $\beta$ signaling enables robust osteogenesis of autologous GMSCs to successfully repair minipig severe maxillofacial bone defects. Stem Cell Res Ther 2019;10:172.

131.Pizzicannella J, Diomede F, Gugliandolo A, et al. 3D Printing PLA/Gingival Stem Cells/ EVs Upregulate miR2861 and -210 during Osteoangiogenesis Commitment. Int J Mol Sci 2019;20:3256.

132. Diomede F, Gugliandolo A, Cardelli P, et al. Threedimensional printed PLA scaffold and human gingival stem cell-derived extracellular vesicles: a new tool for bone defect repair. Stem Cell Res Ther 2018;9:104.

133. Su Y, Chen C, Guo L, et al. Ecological Balance of Oral Microbiota Is Required to Maintain Oral Mesenchymal Stem Cell Homeostasis. Stem Cells 2018;36:551-61.

134.Li J, Xu SQ, Zhang K, et al. Treatment of gingival defects with gingival mesenchymal stem cells derived from human fetal gingival tissue in a rat model. Stem Cell Res Ther 2018;9:27.

135.Zhang Y, Shi S, Xu Q, et al. SIS-ECM Laden with GMSCDerived Exosomes Promote Taste Bud Regeneration. J Dent Res 2019;98:225-33.

136.Xu Q, Shanti RM, Zhang Q, et al. A Gingiva-Derived Mesenchymal Stem Cell-Laden Porcine Small Intestinal Submucosa Extracellular Matrix Construct Promotes Myomucosal Regeneration of the Tongue. Tissue Eng Part A 2017;23:301-12.

137.Zhang Q, Nguyen PD, Shi S, et al. 3D bio-printed scaffold-free nerve constructs with human gingiva- derived mesenchymal stem cells promote rat facial nerve regeneration. Sci Rep 2018;8:6634.

138.Zhang Q, Nguyen PD, Shi S, et al. Neural Crest StemLike Cells Non-genetically Induced from Human GingivaDerived Mesenchymal Stem Cells Promote Facial Nerve Regeneration in Rats. Mol Neurobiol 2018;55:6965-83.

139.Zhang J, Ding H, Liu X, et al. Dental Follicle Stem Cells:

Tissue Engineering and Immunomodulation. Stem Cells Dev 2019;28:986-94.

140.Hong H, Chen X, Li K, et al. Dental follicle stem cells rescue the regenerative capacity of inflamed rat dental pulp through a paracrine pathway. Stem Cell Res Ther 2020;11:333.

141. Yang H, Li J, Hu Y, et al. Treated dentin matrix particles combined with dental follicle cell sheet stimulate periodontal regeneration. Dent Mater 2019;35:1238-53.

142. Rezai-Rad M, Bova JF, Orooji M, et al. Evaluation of bone regeneration potential of dental follicle stem cells for treatment of craniofacial defects. Cytotherapy 2015;17:1572-81.

143. Nie L, Yang X, Duan L, et al. The healing of alveolar bone defects with novel bio-implants composed of AdBMP9-transfected rDFCs and CHA scaffolds. Sci Rep 2017;7:6373.

144.Zuolin J, Hong Q, Jiali T. Dental follicle cells combined with beta-tricalcium phosphate ceramic: a novel available therapeutic strategy to restore periodontal defects. Med Hypotheses 2010;75:669-70.

145.Hilkens P, Bronckaers A, Ratajczak J, et al. The Angiogenic Potential of DPSCs and SCAPs in an In Vivo Model of Dental Pulp Regeneration. Stem Cells Int 2017;2017:2582080.

146.Zhuang X, Ji L, Jiang H, et al. Exosomes Derived from Stem Cells from the Apical Papilla Promote DentinePulp Complex Regeneration by Inducing Specific Dentinogenesis. Stem Cells Int 2020;2020:5816723.

147.Li G, Han N, Zhang X, et al. Local Injection of Allogeneic Stem Cells from Apical Papilla Enhanced Periodontal Tissue Regeneration in Minipig Model of Periodontitis. Biomed Res Int 2018;2018:3960798.

148.Li G, Han N, Yang H, et al. SFRP2 promotes stem cells from apical papilla-mediated periodontal tissue regeneration in miniature pig. J Oral Rehabil 2020;47 Suppl 1:12-8.

149. Nada OA, El Backly RM. Stem Cells From the Apical Papilla (SCAP) as a Tool for Endogenous Tissue Regeneration. Front Bioeng Biotechnol 2018;6:103. 150.Pelissari C, Paris AFC, Mantesso A, et al. Apical Papilla 
Cells Are Capable of Forming a Pulplike Tissue with Odontoblastlike Cells without the Use of Exogenous Growth Factors. J Endod 2018;44:1671-6.

151.Xing X, Han S, Li Z, et al. Emerging role of exosomes in craniofacial and dental applications. Theranostics 2020;10:8648-64.

152.Lv L, Sheng C, Zhou Y. Extracellular vesicles as a novel therapeutic tool for cell-free regenerative medicine in oral rehabilitation. J Oral Rehabil 2020;47 Suppl 1:29-54.

153. Diomede F, Gugliandolo A, Scionti D, et al. Biotherapeutic Effect of Gingival Stem Cells Conditioned Medium in Bone Tissue Restoration. Int J Mol Sci 2018;19:329.

154.Zheng J, Kong Y, Hu X, et al. MicroRNA-enriched small extracellular vesicles possess odonto-immunomodulatory properties for modulating the immune response of macrophages and promoting odontogenesis. Stem Cell Res Ther 2020;11:517.

155. Wen B, Huang Y, Qiu T, et al. Reparative Dentin Formation by Dentin Matrix Proteins and Small Extracellular Vesicles. J Endod 2021;47:253-62.

156. Shi W, Guo S, Liu L, et al. Small Extracellular Vesicles from Lipopolysaccharide-Preconditioned Dental Follicle Cells Promote Periodontal Regeneration in an Inflammatory Microenvironment. ACS Biomater Sci Eng 2020;6:5797-810.

157. Gomes ME, Rodrigues MT, Domingues RMA, et al. Tissue Engineering and Regenerative Medicine: New Trends and Directions-A Year in Review. Tissue Eng Part B Rev 2017;23:211-24.

\section{doi: $10.21037 /$ fomm-21-10}

Cite this article as: He P, Zhang Q, Motiwala FI, Shanti RM, Chang BM, Le AD. Potential application of dental stem cells in regenerative reconstruction of oral and maxillofacial tissues: a narrative review. Front Oral Maxillofac Med 2022;4:14.
158. Thompson M, Mei SHJ, Wolfe D, et al. Cell therapy with intravascular administration of mesenchymal stromal cells continues to appear safe: An updated systematic review and meta-analysis. EClinicalMedicine 2020;19:100249.

159.Liao J, Chen X, Li Y, et al. Transfer of bonemarrow-derived mesenchymal stem cells influences vascular remodeling and calcification after balloon injury in hyperlipidemic rats. J Biomed Biotechnol 2012;2012:165296.

160. Agarwal S, Loder S, Cholok D, et al. Surgical Excision of Heterotopic Ossification Leads to Re-Emergence of Mesenchymal Stem Cell Populations Responsible for Recurrence. Stem Cells Transl Med 2017;6:799-806.

161.Dlouhy BJ, Awe O, Rao RC, et al. Autograft-derived spinal cord mass following olfactory mucosal cell transplantation in a spinal cord injury patient: Case report. J Neurosurg Spine 2014;21:618-22.

162. Varderidou-Minasian S, Lorenowicz MJ. Mesenchymal stromal/stem cell-derived extracellular vesicles in tissue repair: challenges and opportunities. Theranostics 2020;10:5979-97.

163. Gurunathan S, Kang MH, Jeyaraj M, et al. Review of the Isolation, Characterization, Biological Function, and Multifarious Therapeutic Approaches of Exosomes. Cells 2019;8:307.

164. Shu S, Yang Y, Allen CL, et al. Purity and yield of melanoma exosomes are dependent on isolation method. J Extracell Vesicles 2020;9:1692401. 